\title{
Auxerre, la cathédrale Saint-Étienne. Suivi archéologique des travaux de restauration et analyses de laboratoire
}

\section{Sylvain Aumard}

\section{(2) OpenEdition \\ 1 Journals}

\section{Édition électronique}

URL : https://journals.openedition.org/cem/863

DOI : $10.4000 /$ cem. 863

ISSN : 1954-3093

Éditeur

Centre d'études médiévales Saint-Germain d'Auxerre

\section{Édition imprimée}

Date de publication : 15 août 2004

ISSN : 1623-5770

Référence électronique

Sylvain Aumard, «Auxerre, la cathédrale Saint-Étienne. Suivi archéologique des travaux de restauration et analyses de laboratoire ", Bulletin du centre d'études médiévales d'Auxerre | BUCEMA [En ligne], 8 | 2004, mis en ligne le 13 décembre 2006, consulté le 22 septembre 2022. URL : http:// journals.openedition.org/cem/863; DOI : https://doi.org/10.4000/cem.863

Ce document a été généré automatiquement le 22 septembre 2022.

\section{(c) (i) (2)(2)}

Creative Commons - Attribution - Pas d'Utilisation Commerciale - Partage dans les Mêmes Conditions 4.0 International - CC BY-NC-SA 4.0

https://creativecommons.org/licenses/by-nc-sa/4.0/ 


\title{
Auxerre, la cathédrale Saint- Étienne. Suivi archéologique des travaux de restauration et analyses de laboratoire
}

\author{
Sylvain Aumard
}

1 Dans la continuité du suivi archéologique des travaux de restauration entrepris en 2002-2003, plusieurs axes de travail ont été poursuivis en 2003-2004.

2 Tout d'abord, alors que paraissait le précédent numéro de ce bulletin, les reins de voûtes faisaient l'objet d'un déblaiement systématique. Malgré nos espoirs d'y retrouver des témoins de la première couverture, bien calés en stratigraphie, nos observations ont été un peu décevantes. Il semble en effet que les voûtes aient anciennement fait l'objet d'un nettoyage; quelques feuilles du journal Le Bourguignon, daté de novembre 1907, ont été mises au jour. Toutefois, dans les reins des deux premières travées de la nef, des éléments de sculptures ont été retrouvés avec des débris d'ardoise, le tout en provenance - semble-t-il - de la tour nord (fragments de pinacle? et de gargouille). En outre, une importante quantité de lattes fendues de l'ancien voligeage a été presque intégralement conservée pour étude a posteriori. Dans le but de mieux étudier le comblement de ces reins de voûtes, et à la demande du conseil scientifique, deux d'entre eux ont été mis en réserve contre la croisée ( $6^{\mathrm{e}}$ travée).

3 L'autre volet important engagé en 2003 concerne les analyses dendrochronologiques ${ }^{1}$ sur les bois de charpente et les analyses archéomagnétiques ${ }^{2}$ sur les tuiles. Les premières ont permis de compléter un important corpus de prélèvements s'élevant à environ 200 bois qui, à ce jour, constitue vraisemblablement le plus important à l'échelle de la France, dans un contexte monumental. Si cette étude a confirmé les premières datations établies sur les trois chantiers successifs de la charpente de la nef, elle a surtout confirmé et précisé les observations de nos confrères de Stuttgart sur les différents états de réfection de la croisée. Bien entendu, un corpus de données de cette ampleur a permis d'étayer solidement le référentiel régional des dendrochronologues; 
ce dernier constitue désormais une base de travail incontournable pour étudier la provenance géographique des bois de charpente icaunais.

4 Les analyses archéomagnétiques de 200 tuiles ${ }^{3}$ ont demandé un travail de préparation(classement typologique, inventaire et conditionnement en caisses) avant transport à Rennes par les services de la Ville d'Auxerre. Les résultats confirment d'abord l'homogénéité des lots typologiques établis et, par là, la pertinence des critères discriminants employés. Ils confirment ensuite l'ancienneté des modèles dont la forme et les dimensions paraissent standardisées; ils valident donc, ici, la méthode d'échantillonnage mise en œuvre au moment de la dépose de la couverture. Enfin, ils tendent à montrer que la date de fabrication des tuiles parait être en rapport avec celle de la charpente de la nef, écartant ainsi toute possibilité de remploi massif ou de réfection importante à une date ancienne. Ce travail sur les matériaux de couverture a fait l'objet de deux présentations dans le cadre de la formation continue de l'Institut national du Patrimoine: en septembre 2003 lors d'un séminaire sur les couvertures anciennes et en mars 2004 lors d'un autre séminaire consacré à l'archéologie du bâti.

Toujours dans le souci d'accompagner les restaurations d'une démarche scientifique au plus près des réalités du terrain, deux sondages ont été réalisés fin mars/début avril au pied des bas-côtés sud de la cathédrale. Leur objectif était de procéder, avant le démarrage d'une tranche de 24 mois de travaux, à une reconnaissance archéologique $\mathrm{du}$ sol en prévision de l'enfouissement d'un drain collectant les eaux de pluies de l'édifice.

\section{NOTES}

1.Didier PousSet et Christine LoCATELLi (Centre régional de restauration et de conservation des œuvres d'art de Vesoul), doctorants au Laboratoire de ChronoÉcologie de Besançon (UMR 6565).

2.- Philippe LANOS, Laboratoire d'archéomagnétisme de l'Université de Rennes/ CNRS.

3.En complément du premier lot d'une centaine d'éléments préparés en novembre 2002.

\section{INDEX}

Index géographique : France/Auxerre

Mots-clés : cathédrale, Etienne (saint), Saint-Etienne d'Auxerre 